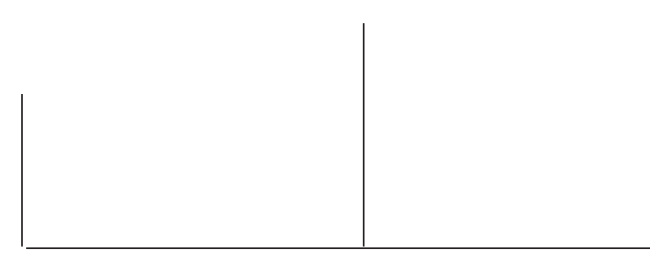

Rev. Latinoam. Psicopat. Fund., X, 2, 332-339

\title{
As "loucuras raciocinantes" e a constituição do campo da paranóia na psicopatologia atual
}

\author{
Mário Eduardo Costa Pereira
}

Esta apresentação tem por objetivo situar o estudo clássico de Sérieux e Capgras sobre as loucuras raciocinantes no contexto da delimitação contemporânea do conceito de "paranóia". Em particular, discute-se o uso feito por Kraepelin desse célebre trabalho na elaboração de sua própria definição de paranóia, apresentada na oitava edição de seu Tratado de Psiquiatria, de 1915.

Palavras-chave: Sérieux, Capgras, loucuras raciocinantes, paranóia 
O célebre trabalho de Paul Sérieux e Joseph Capgras intitulado "As loucuras raciocinantes - o delírio de interpretação", publicado em 1909, constitui um marco decisivo na delimitação dos quadros paranóicos, tais como os concebemos hoje.

Tal conquista da separação entre os quadros de delírio crônico, estruturado, sem deterioração do conjunto da personalidade, por um lado, e as formas paranóides da esquizofrenia, por outro - relativamente autoevidente para a psicopatologia contemporânea - só pôde ser lentamente estabelecida, consolidando-se no início do século XX, a partir da publicação da 8a Edição do Tratado de Kraepelin, a qual, como veremos, no tangente a esse tema, incorpora amplamente a concepção expressa no estudo de Sérieux e Capgras.

Na verdade, o termo "paranóia" tem longa tradição na história da psicopatologia e é necessário remontar às suas origens na Grécia clássica para compormos uma idéia mais clara das transformações que sofreu até chegar a seu uso técnico contemporâneo. Naquele contexto, $\pi \alpha \rho \alpha v o r \alpha$ referia-se antes de tudo ao desvario extremo provocado pelas paixões, não designando, pois, propriamente uma forma particular de loucura, mas a loucura em si, em suas dimensões de delírio e de arrebatamento insensato. Literalmente, "pensar ao largo, de maneira enviesada", a palavra paranóia era empregada tanto na língua comum, como na medicina hipocrática, na qual recebia o sentido genérico de alienação mental.

Permanecendo restrita durante séculos a um uso meramente descritivo e informal, esse termo precisaria aguardar a psiquiatria alemã do século XIX para ser utilizada como conceito nosológico específico, o qual será progressivamente elaborado e delimitado.

Somente em 1772 Vogel resgataria esse termo para o vocabulário médico, referindo-o apenas como sinônimo genérico de "loucura", 


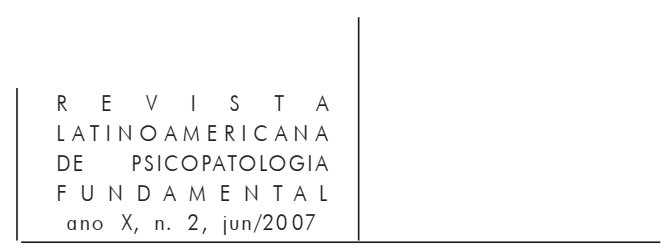

conotação que seria retomada de maneira mais sistemática por Heinroth, em 1818 (cf. Garrabé, 1992).

A idéia de que a "loucura" pudesse não ser unitária, mas um gênero dividido em inúmeras espécies clinicamente delimitáveis, foi sendo implantada de forma muito lenta antes de tornar-se universalmente aceita no pensamento psiquiátrico. No início do século XIX, a psiquiatria européia foi marcada por intensas discussões em torno da chamada "psicose única" (Einheitpsychose), conceito que teve em Wilhelm Griesinger seu principal defensor e propagador. Segundo seu ponto de vista, todas as psicoses clinicamente identificáveis constituiriam apenas diferentes etapas de um mesmo processo psicopatológico. O termo "paranóia", em sua teoria, designava um delírio crônico, secundário a um episódio de melancolia ou de mania, podendo aquele estar associado ou não a fenômenos alucinatórios. Dessa forma, os fenômenos afetivos seriam os elementos fundamentais, enquanto o quadro delirante não teria consistência psicopatológica autônoma. O progresso das pesquisas clínicas, contudo, acabaria por demonstrar as limitações da concepção de Griesinger.

Assim, em 1863 Kahlbaum descreve um quadro psicótico no qual a atividade delirante instala-se desde o início, sem ser precedida por manifestações depressivas. Dá a essa condição a denominação de "paranóia", primeira utilização desse termo para designar um transtorno mental específico. Logo após, em 1865, Snell propõe a existência de um estado delirante e alucinatório primário em que o tema da perseguição é mais freqüente que as idéias de grandeza e ao qual denominará de primäre Wahnsinn (cf. Postel \& Quetel, 1983, p. 336). A partir de 1879, Kraft-Ebing passa reservar o termo "paranóia" para designar os delírios sistematizados, admitindo também que esses poderiam ser primários.

No contexto psiquiátrico francês, o termo "paranóia" - considerado excessivamente vago - teve uma implantação bem mais tardia, embora os fatos clínicos aos quais se refere já tivessem sido amplamente estudados pela tradição psiquiátrica daquele país. Basta evocar, entre outros, o trabalho decisivo de Lasègue sobre o delírio das perseguições (1852), os estudos de Morel sobre perturbações interpretativas observadas na loucura hereditária dos degenerados e a distinção estabelecida por Magnan (a partir de 1881) entre os "delírios dos degenerados" e o "delírio crônico de evolução sistemática", para se perceber a grande importância que o estudo dos delírios crônicos teve na psiquiatria francesa. Dispondo, portanto, de sua própria tradição nesse campo, foi somente a partir de 1895, com o emprego por Séglas do termo "paranóia" para designar as loucuras sistemáticas, que essa palavra passaria a fazer parte do vocabulário habitual da psicopatologia de seu país.

Com a universalização da necessidade de se desvendar as espécies do gênero "loucura" e com a proliferação dos estudos, sobretudo franceses e alemães, sobre 


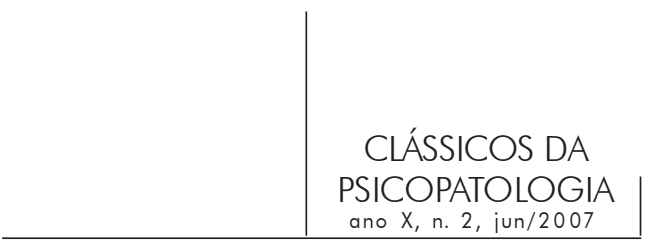

os delírios crônicos sistematizados e sobre os quadros psicóticos desestruturantes da personalidade, no final do século XIX, o campo clínico recortado pela denominação "paranóia” era o mais heterogêneo possível. Nos termos do próprio Séglas (1887), "não existe palavra, em psiquiatria, que tenha uma acepção mais vasta e mais mal definida" (apud Claude \& Montassut, 1926, p. 57). Inúmeros quadros psicopatológicos - muito diferentes em sua natureza, mas que apresentavam um quadro delirante com temas de perseguição e idéias de grandeza - terminavam por ser genericamente designados pelo termo "paranóia", o que fazia com que esse conceito perdesse inteiramente seu valor discriminativo. Assim, foram descritas paranóias agudas e crônicas, primárias e secundárias, acompanhadas ou não de alucinações e, ainda, correlativas a estados de confusão mental primária, a estados de intoxicação, ou então, segundo algumas descrições, conduzindo a um desfecho demencial. Foi necessário aguardar Kraepelin para que um mínimo de clareza conceitual pudesse ser implantado.

Na passagem do século XIX para o século XX, Emil Kraepelin era a maior autoridade científica internacional no que se referia à nosografia psiquiátrica. Apoiado em um método de rigorosa observação clínica, a qual não se restringia apenas o momento atual do quadro apresentado pelo paciente, mas focalizando também as transformações do quadro ao longo do tempo, o mestre alemão propunha-se a construir um sistema de diagnósticos psiquiátricos fundado nas características e regularidades clínicas diretamente observáveis segundo uma perspectiva diacrônica (cf. Pereira, 2001a). Do ponto de vista metodológico, buscava ativamente não levar em consideração quaisquer hipóteses etiológicas ou especulações e natureza psicológica, restringindo-se aos dados imediatamente observáveis. Segundo seu ponto de vista, a depuração descritiva dos elementos regulares verificados no acompanhamento clínico tenderia a isolar entidades mórbidas específicas.

Sua obra principal, o Tratado de Psiquiatria (Lehrbuch der Psychiatrie), teve oito edições revisadas e substancialmente ampliadas durante a vida de seu autor. Em sua quarta edição, publicada em 1893, Kraepelin introduz o conceito de demencia praecox, expressão anteriormente utilizada por Morel para designar um quadro clínico de imobilização súbita das faculdades psíquicas ocorrendo durante a juventude. Com essa expressão, o autor francês buscava apenas enfatizar o aspecto cronológico juvenil da instalação dessa alteração psíquica, sem pretender fazer do termo a denominação de uma nova entidade psicopatológica. Essa é a inovação proposta por Kraepelin com o resgate desse termo de Morel.

A clássica edição do Tratado (6. ed.), publicada em 1899, estabelece uma definição bastante ampla da "demência precoce", nela incluindo os delírios crônicos sistematizados, de caráter persecutório, dando a esse quadro específico 


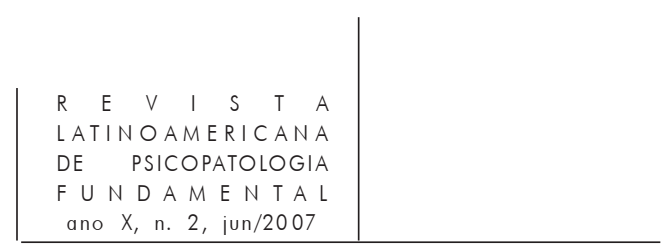

o nome de "demência paranóide". A dementia paranoides englobava, portanto, aquilo que viria, após Bleuler, a ser conhecido como esquizofrenia em sua forma paranóide, bem como a paranóia em geral e o delírio crônico de evolução sistemática, de Magnan. Além disso, o critério evolutivo empregado por Kraepelin indicava que o destino desses sujeitos era um estado terminal de desagregação mental, o que era contraditório com as concepções clássicas da escola francesa, que sustentavam a perservação da personalidade malgrado o curso crônico e incurável do transtorno. Compreende-se, assim, que a inclusão por Kraepelin da paranóia, de maneira quase integral, na descrição da forma paranóide da demência precoce (dementia paranoide), tenha sido considerada pelos franceses um esvaziamento da especificidade clínica e nosológica desses quadros.

Dessa forma, o ponto de vista kraepeliniano foi fortemente criticado na França, onde se insistia quanto ao caráter autônomo e primário da paranóia em relação aos quadros delirantes crônicos que conduziam à deterioração do funcionamento psíquico global.

A monografia de Sérieux e Capgras, de 1909, sobre o delírio de interpretação (les folies raisonnantes) inscreve-se, pois, no cerne desse debate. Publicada entre a $6^{\mathrm{a}}$ e a $8^{\mathrm{a}}$ edições do Tratado de Kraepelin, trata-se de um esforço no sentido de ratificar a posição francesa no que se refere à autonomia psicopatológica do delírio sistemático baseado em interpretações delirantes. Seus autores constituem a última geração dos chamados "clássicos franceses".

Paul Sérieux nasceu em Paris, em 1864. Foi aluno de Magnam, tendo defendido uma tese sobre as anomalias dos instintos sexuais. Interessou-se particularmente pelo estudo do alcoolismo, dos psicopatas perigosos e pelos dispositivos institucionais de assistência pública aos alienados. No início do século XX foi um dos responsáveis pela introdução no contexto francês da classificação dos transtornos mentais proposta por Kraepelin, bem como das idéias do mestre de Munique sobre a demência precoce.

Sérieux estabelece uma fecunda parceria científica com seu aluno Capgras, da qual resultariam importantes contribuições no campo da psicopatologia, entre elas o clássico estudo sobre as loucuras raciocinantes ou delírio de interpretação. Com esse trabalho, os dois viriam a se tornar nomes de referência obrigatória para todo pesquisador interessado pela psicopatologia da paranóia. Mesmo Lacan (1932), em sua tese de doutorado que tinha por tema a psicose paranóica em suas relações com a personalidade, faz um agradecimento explícito a esses psiquiatras pela acolhida que dedicaram a seus pontos de vista e afirmando que "não se pode, de resto, tratar do sujeito de nossa tese sem se sentir devedor em relação a seus trabalhos" (p. 16).

Nesse estudo, os autores consideram, portanto, que o delírio de interpretação constitui uma entidade psicopatológica autônoma. Trata-se, segundo eles, de uma 


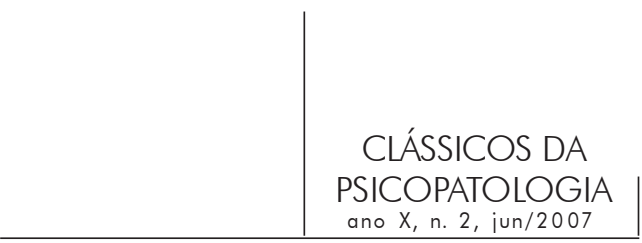

psicose delirante crônica, sistematizada, de caráter não alucinatório que se caracteriza por:

1) multiplicidade e organização de interpretações delirantes;

2) ausência ou penúria de alucinações (contingentes);

3) persistência da lucidez e da atividade psíquica;

4) evolução através da extensão progressiva das interpretações;

5) incurabilidade, sem demência terminal. (Sérieux \& Capgras, p. 4-5)

O elemento fundamental dessa condição psicopatológica é, pois, a multiplicidade das interpretações delirantes, ou seja, "um raciocínio falso que tem como ponto de partida uma sensação real, um fato exato, o qual em virtude de associações de idéias ligadas às tendências e à afetividade e através de induções ou deduções erradas, acaba por adquirir para o doente uma significação pessoal, pela qual tudo se coloca invencivelmente a ele relacionado".

Os autores destacam, assim, as loucuras raciocinantes - estas resultantes da organização cada vez mais complexa do delírio de interpretação, elaborado a partir de interpretações delirantes - dos delírios agudos e secundários. Nesse mesmo texto, o delírio de interpretação é separado do delírio de reivindicação, o qual corresponde ao Querulanten Wahn (delírio de querelância), dos alemães.

Kraepelin, na oitava edição de seu Tratado (1915) termina por aderir às teses de Sérieux e Capgras, utilizando-as para dar a forma definitiva de sua separação entre os delírios crônicos primários e sistematizados (paranóia) e as formas paranóides da demência precoce. Concede, assim, à escola francesa, na sua delimitação da paranóia, a extensão progressiva das interpretações falsas e a raridade das alucinações. A derradeira formulação kraepeliniana sobre a paranóia funde-se, no essencial, com a loucura raciocinante de Sérieux e Capgras, distingue-a da demência precoce e termina por delimitar nossa maneira atual de conceber o campo dos fenômenos paranóicos e paranóides.

Convém lembrar que o estudo realizado por Freud sobre o caso Schreber (1911), ocorre antes dessa formulação final sobre a nosografia da paranóia e da demência precoce de Kraepelin e que os comentários freudianos ali apresentados sobre as definições de "paranóia", "demência precoce", "parafrenia” e "demência paranóide" devem ser lidos à luz desse contexto histórico, uma vez que sua

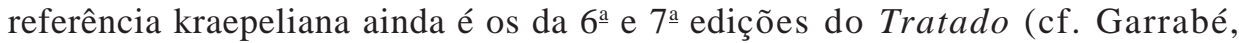
1992, p. 73-7).

A presente edição da Revista Latinoamericana de Psicopatologia Fundamental traz a tradução da "Introdução" da monografia de Sérieux e Capgras sobre as loucuras raciocinantes, de 1909, na qual são resumidas as principais propostas inovadoras desse grande clássico da psicopatologia. 


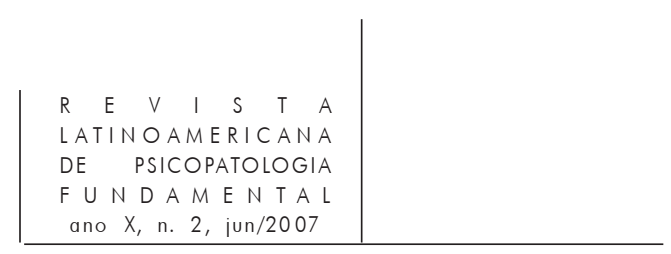

\section{Referências}

BERCHERIE, P. Histoire et structure du savoir psychiatrique: les fondements de la clinique - I. Tournai: Editions Universitaires, 1991.

BerRios, G. The History of the Mental Symptoms. Cambridge: Cambridge University Press, 1996.

Claude, H. \& Montassut, M. Délimitation de la paranoïa légitime. L'encéphale, p. 5763, 1926.

Garrabé, J. Histoire de la schizophénie. Paris: Seghers, 1992.

Kraepelin, E. Introduction à la psychiatrie clinique. Paris: Navarin, 1984.

La demencia precoz. v. I e II. Buenos Aires: Polemos Editorial, 1996.

Lacan, J. Structure des psychoses paranö̈aques. Semaine des Hôpitaux de Paris, juillet 1931, n. 14, p. 437-45. Seuil, 1980.

De la psychose paranö̈aque dans ses rapports avec la personalité. Paris: 1981.

Le séminaire. Livre III. Les psychoses (texte établi par J.-A. Miller). Paris: Seuil,

Moreira, J. \& Peixoto, A. A paranóia e as síndromes paranóides. Revista Latinoamericana de Psicopatologia Fundamental, ano IV, n. 2, p. 134-67, jun./2001.

ODA, A. M. G. R. As loucuras com método: Sérieux e Capgras e a descrição da psicose crônica baseada em interpretações delirantes. In: Dalgalarrondo, P.; Sonenreich, C. \& ODA, A. M. R. História da psicopatologia: textos originais de grandes autores. São Paulo: Lemos, 2004. p. 77-83.

Pereira, M. E. C. Bleuler e a invenção da esquizofrenia. Revista Latinoamericana de Psicopatologia Fundamental, ano III, n. 1, p. 158-63, mar./2000.

Kraepelin e a criação do conceito de "Demência Precoce". Revista Latinoamericana de Psicopatologia Fundamental, ano IV, n. 4, p. 126-9, dez./2001a.

Introdução a "Melancolia", de Emil Kraepelin. Revista da Associação Psicanalítica de Porto Alegre. Porto Alegre, n. 21, p. 165-9, $2001 \mathrm{~b}$.

Pessotti, I. A loucura e as épocas. Rio de Janeiro: Editora 34, 1994.

Os nomes da loucura. Rio de Janeiro: Editora 34, 1999.

Postel, J. \& Quetel, C. (org.). Nouvelle histoire de la psychiatrie. Toulouse: Privat, 1983.

SÉRIEUX, P. \& CAPGRAS, J. As loucuras raciocinantes - o delírio de interpretação: introdução. In: Dalgalarrondo, P.; Sonenreich, C. \& Oda, A. M. R. História da psicopatologia: textos originais de grandes autores. São Paulo: Lemos, 2004. p. 77-83. 


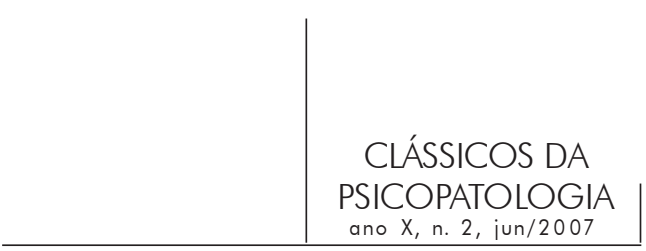

Resumos

Esta presentación tiene como objetivo situar el estudio clásico de Sérieux y Capgras sobre las locuras raciocinantes en el contexto de la delimitación contemporánea del concepto de "paranoia". En particular se discute el uso que Kraepelin ha hecho de ese trabajo célebre en la elaboración de su propia definición de paranoia, presente en la octava edición de su Tratado de Psiquiatría, de 1915.

Palabras claves: Sérieux, Capgras, locuras raciocinantes, paranoia

L'objectif de cette présentation est de situer l'étude classique de Sérieux et Capgras sur les folies raisonnantes dans le contexte de la délimitation contemporaine du concept de paranoïa. En particulier, on discute ici l'emploi fait par Kraepelin de ce travail devenu célèbre dans l'élaboration de sa propre définition de paranoüa, présentée à la huitième édition de son Traité de Psychiatrie, en 1915.

Mots clés: Sérieux, Capgras, folies raisonnantes, paranoïa

This article is aimed at discussing Serieux and Capgras's classical study on rationaling madness in the context of the contemporary delimitation of the concept of "paranoia." In particular, the author discusses Kraepelin's use of this famous article in drawing up his own definition of paranoia, included in the eighth edition of his Treatise on Psychiatry, written in 1915.

Key words: Sérieux, Capgras, "Rationaling madness", paranoia 